UDC 342.4:347.471

LBC 67.400 .4

\title{
REGULATORY IMPACT ASSESSMENT AND PUBLIC EXAMINATION: CORRELATION OF THE CONCEPTS
}

\author{
Anna A. Goncharova \\ Volgograd State University, Volgograd, Russian Federation
}

\begin{abstract}
Introduction: public expertise as a competent participation of citizens in the management of the state affairs has a great potential in improving the quality of the decisions and regulatory legal acts. The regulatory impact assessment has the same objective, and at the stage of public consultations is implemented by the same subjects as public expertise. In this regard, it is necessary to identify the correlation of these concepts, to determine whether the regulatory impact assessment should only be carried out by interested subjects, or also by competent ones, which determined the purpose of this work. Methods: the methodological framework for the study is a set of methods of scientific knowledge, among which the main are the methods of analysis, formal-logical and comparative-legal ones. Results: the assessment of the regulatory impact in general and the stage of public consultations in particular in terms of their relationship with the procedure of public expertise are considered; the opinions of the scientists on this issue, as well as the provisions of the regulatory legal acts are analyzed. Conclusions: it is established that at present the procedure of the regulatory impact assessment is not public expertise. At the same time, these institutions are quite close. In the future, it is possible to conduct not only public discussions, but also full expert studies on the part of the civil society within the framework of the regulatory impact assessment.
\end{abstract}

Key words: public control, public discussion, public expertise, regulatory impact assessment, public consultations.

Citation. Goncharova A.A. Regulatory Impact Assessment and Public Examination: Correlation of the Concepts. Legal Concept, 2018, vol. 17, no. 3, pp. 79-82. DOI: https://doi.org/10.15688/lc.jvolsu.2018.3.11

УДК 342.4:347.471

ББК 67.400 .4

\section{ОЦЕНКА РЕГУЛИРУЮЩЕГО ВОЗДЕЙСТВИЯ И ОБЩЕСТВЕННАЯ ЭКСПЕРТИЗА: СООТНОШЕНИЕ ПОНЯТИЙ}

\author{
Анна Александровна Гончарова \\ Волгоградский государственный университет, г. Волгоград, Российская Федерация
}

\begin{abstract}
Введение: общественная экспертиза как компетентное участие граждан в управлении делами государства имеет большой потенциал в области повышения качества принимаемых решений и нормативных правовых актов. Оценка регулирующего воздействия имеет ту же цель, а на стадии публичных консультаций реализуется теми же субъектами, что и общественная экспертиза. В связи с этим необходимо выявить соотношение данных понятий, определить, должна ли оценка регулирующего воздействия проводиться только лишь заинтересованными, или же еще и компетентными субъектами, что и определило цель настоящей работы. Методы: методологическую основу проведенного исследования составляет совокупность методов научного познания, среди которых основное место занимают методы анализа, формально-логический и сравнительно-правовой. Результаты: рассмотрена оценка регулирующего воздействия в целом и стадия публичных консультаций в частности с точки зрения их соотношения с процедурой общественной экспертизы, проанализированы мнения ученых по данному вопросу, а также положения нормативных правовых актов. 。ै Выводы: установлено, что в настоящее время процедура оценки регулирующего воздействия не является общественной экспертизой. В то же время данные институты достаточно близки. В перспективе возможно 帘 проведение в рамках оценки регулирующего воздействия не только общественных обсуждений, но и полно() ценных экспертных исследований со стороны гражданского общества.
\end{abstract}




\section{ТЕОРИЯ И ПРАКТИКА ГОСУДАРСТВЕННО-ПРАВОВОГО РАЗВИТИЯ}

Ключевые слова: общественный контроль, общественное обсуждение, общественная экспертиза, оценка регулирующего воздействия, публичные консультации.

Цитирование. Гончарова А. А. Оценка регулирующего воздействия и общественная экспертиза: соотношение понятий // Legal Concept = Правовая парадигма. -2018 . - T. 17, № 3. - C. 79-82. - DOI: https://doi.org/ 10.15688/lc.jvolsu.2018.3.11

\section{Введение}

Государство стремится повысить качество принимаемых нормативных правовых актов и социально значимых решений различными способами, в том числе привлекая субъектов гражданского общества. В настоящее время активно развивается сравнительно молодой институт общественной экспертизы, который предполагает компетентное участие граждан и общественных объединений в управлении делами государства. С 2010 г. официально реализуется процедура оценки регулирующего воздействия (далее - ОРВ) на федеральном, а с 2011 г. и на региональном уровнях, которая также предполагает участие общественности на определенных стадиях ее проведения. Возникает вопрос о соотношении общественной экспертизы и оценки регулирующего воздействия. От ответа на данный вопрос зависит статус результатов публичных консультаций в рамках ОРВ.

\section{Оценка регулирующего воздействия - вид общественной экспертизы?}

В литературе можно встретить мнение, что ОРВ представляет собой общественную экспертизу [4, с. 106]. Данная точка зрения встречается в социологической литературе и нуждается в критической оценке с точки зрения юридической науки.

Задачей ОРВ является анализ проблем и целей государственного регулирования, выявление и оценка альтернативных вариантов решения проблем, а также определение связанных с ними выгод и издержек субъектов предпринимательской среды, подвергающихся воздействию государственного регулирования, для выбора наиболее эффективного варианта государственного регулирования [1, c. 134]. В целях обеспечения учета мнения максимально широкого круга адресатов действия проекта акта и формирования объективной позиции общества в отношении готовяще- гося документа в рамках процедуры ОРВ проводятся публичные консультации в отношении проектов актов в виде их общественного обсуждения. Оценка регулирующего воздействия осуществляется при непосредственном участии институтов гражданского общества: публичные консультации являются неотъемлемой и важнейшей частью процедуры ОРВ. ОРВ проводится федеральными органами исполнительной власти - разработчиками проекта, а заключение по результатам ОРВ готовит Министерство экономического развития. Представляется справедливой позиция Д.С. Вечернина, который признает ОРВ одной из форм экспертной деятельности, одновременно сочетающей в себе возможности обеспечения обратной связи с обществом [2, c. 23]. Однако общественной экспертизой процедура ОРВ не является, поскольку проводится она государственными органами, а участие общественности реализуется лишь на определенном этапе. Можно предположить, что предоставляемые в рамках публичного обсуждения мнения участников обсуждений являются общественными экспертизами оцениваемого проекта акта. Данное предположение имеет право на существование и в силу того, что на информационном портале об оценке регулирующего воздействия http://orv.gov.ru в документе для регистрации в качестве участника публичных консультаций используется формулировка «Единая база экспертов предпринимательского сообщества по оценке регулирующего воздействия проектов нормативных правовых актов». То есть участники названы экспертами. Возникает вопрос: являются ли они таковыми? От ответа на данный вопрос будет зависеть и статус выражаемого ими мнения: оно будет либо экспертным заключением, либо мнением в рамках общественного обсуждения. Основным критерием, позволяющим отличить общественную экспертизу от иных форм общественного контроля, является компетентность экспертов: общественная экспертиза является обществен- 
А.А. Гончарова. Оценка регулирующего воздействия и общественная экспертиза: соотношение понятий

ной лишь по форме, но не по содержанию. К участникам публичных консультаций не предъявляется никаких особых требований, регистрация на сайте является формальной процедурой допуска к обсуждению проекта акта. Публичные консультации проводятся с целью сбора мнений всех заинтересованных лиц относительно обоснованности окончательного выбора варианта предлагаемого правового регулирования. Исходя из сказанного, ответы на вопросы в рамках публичных консультаций проекта нормативного акта, подлежащего ОРВ и размещенного на сайте http://regulation.gov.ru для публичных обсуждений, не являются общественными экспертизами и представляют собой иную форму общественного контроля - общественные обсуждения. Хотя участников общественных обсуждений и называют экспертами предпринимательского сообщества по оценке регулирующего воздействия, они таковыми не являются, поскольку их компетентность не всегда соответствует уровню эксперта, а даваемое заключение является лишь их позицией по вопросам, сформулированным в целях выявления мнения заинтересованных лиц и сбора предложений в рамках общественного обсуждения.

\section{Перспективы развития правового регулирования}

На сегодняшний день процедура ОРВ не является общественной экспертизой, но в перспективе она может стать таковой, и от бизнес-сообщества уже поступали подобные предложения. Так, вице-президент по корпоративным и правовым вопросам ОАО «МТС» Руслан Ибрагимов в интервью ОРЕС.ru высказал идею «возложить оценку регулирующего воздействия дополнительно на пул независимых экспертов из числа наиболее авторитетных в профессиональной среде квалифицированных юристов, экономистов, отраслевых специалистов и, возможно, аудиторов» [3]. Экспертный пул в таком составе сможет провести грамотную всестороннюю экспертизу законопроектов и подготовить заключение с прогнозом последствий принятия законопроекта, в том числе в цифрах. Кроме того, благодаря внедрению рассматриваемого предложения ОРВ будут подвергаться проекты нор- мативных актов, вносимые не только Правительством РФ, но и иными субъектами права законодательной инициативы.

\section{СПИСОК ЛИТЕРАТУРЫ}

1. Батуева, Д. В. Институт оценки регулирующего воздействия в российской практике / Д. В. Батуева // Государственное и муниципальное управление в XXI веке: теория, методология, практика. 2015. - № 19. - С. 133-138.

2. Вечернин, Д. С. Эволюция институга оценки регулирующего воздействия: проблемы и перспективы / Д. С. Вечернин // Вестник МГОУ. Серия «Юриспруденция». - 2014. - № 4. - С. 22-28.

3. Как нам реорганизовать общественную экспертизу // Научно-образовательный портал IQ Национального исследовательского университета «Высшая школа экономики». - Электрон. текстовые дан. - Режим доступа: https://iq.hse.ru/news/ 177671900.html (дата обращения: 04.05.2018). - Загл. с экрана.

4. Меньшикова, Г. А. Оценка регулирующего воздействия как общественная экспертиза управленческих решений / Г. А. Меньшикова, А. А. Миронова, Н. А. Пруель // Вестник СПбГУ. Серия 12, Социология. -2016. - Вып. 3. - С. 101-117.

\section{REFERENCES}

1. Batueva D.V. Institut otsenki reguliruyushchego vozdeystviya $\mathrm{v}$ rossiyskoy praktike [Institute for regulatory impact assessment in Russian practice]. Gosudarstvennoe i munitsipalnoe upravlenie v XXI veke: teoriya, metodologiya, praktika, 2015, no. 19 , pp. 133-138.

2. Vechernin D.S. Evolyutsiya instituta otsenki reguliruyushchego vozdeystviya: problemy i perspektivy [Evolution of Regulatory Impact Assessment: Challenges and Prospects]. Vestnik MGOU. Seriya «Yurisprudentsiya», 2014, no. 4, pp. 22-28.

3. Kak nam reorganizovat obshchestvennuyu ekspertizu [How Can We Reorganize Social Expertise]. Nauchno-obrazovatelnyy portal IQ Natsionalnogo issledovatelskogo universiteta "Vysshaya shkola ekonomiki». URL: https://iq.hse.ru/news/177671900.html (accessed 4 May 2018).

4. Menshikova G.A., Mironova A.A., Pruel N.A. Otsenka reguliruyushchego vozdeystviya kak obshchestvennaya ekspertiza upravlencheskikh resheniy [Regulatory Impact Assessment as a Public Examination of Managerial Decisions]. Vestnik $S P b G U$. Seriya 12, Sotsiologiya, 2016, iss. 3, pp. 101-117. 


\section{ТЕОРИЯ И ПРАКТИКА ГОСУДАРСТВЕННО-ПРАВОВОГО РАЗВИТИЯ}

\section{Information about the Author}

Anna A. Goncharova, Postgraduate Student, Department of Constitutional and Municipal Law, Volgograd State University, Prosp. Universitetsky, 100, 400062 Volgograd, Russian Federation, anutka3402@yandex.ru.

\section{Информация об авторе}

Анна Александровна Гончарова, аспирант кафедры конституционного и муниципального права, Волгоградский государственный университет, просп. Университетский, 100, 400062 г. Волгоград, Российская Федерация, anutka3402@yandex.ru. 